\title{
Paleontology and Cornets: Thoughts on Material Cultural Evolution
}

\author{
Niles Eldredge
}

Published online: 16 August 2011

(C) Springer Science+Business Media, LLC 2011

I've been an amateur trumpet and cornet player since the fourth grade. That's also around the time when, like many of my friends, I fell in love with dinosaurs. I went on to become a paleontologist focused on what fossils can tell us about the nature of the evolutionary process. But I never lost my love of trumpets - and their smaller, more compact cousins, cornets. I went on to amass a collection of hundreds of them, from the oldest to the most modern. My friends tell me the collection, in part arranged on a wall in a room (Fig. 1) where I am writing this essay, is clearly the work of a paleontologist; for the cornets are arranged by style and maker - and show the history - the "evolution"of cornets from the 1820 s to yesterday.

And, unsurprisingly in retrospect, I began to look at cornets as relics of the past - as kinds of man-made "fossils"-or, more accurately, "historical artifacts." And, as with real fossils, I have wondered what these cornets have to tell us about the way artifacts - the things people make- "evolve." Are there regular processes typical of the manufacturing process of particular artifacts that produce similar patterns of historical development-whether in cornets, pianos, down through the entire artifactual spectrum: spear points, cars, computers, and so on, ad infinitum?

I think there are-and so do an increasing number of scholars from many fields: archeology, of course, but also cultural anthropologists and those involved with discovering patterns of inventiveness and change in all manner of products of the modern technological world in which we

\section{N. Eldredge $(\bowtie)$}

The American Museum of Natural History,

Central Park West at 79th St.,

New York 10024, USA

e-mail: epunkeek@amnh.org live. The articles in this Special Issue of Evolution: Education and Outreach, edited by the archeologist Anna Marie Prentiss, reveal some of the diversity in expertise of scholars interested in the field of material cultural evolution.

In what way is "material cultural evolution" an actual form of evolution - as opposed to just "history"? After all, people design and make artifacts; it is not as though cornets exist on their own, reproducing themselves and showing a sort of natural variation that can be "selected"-as of course happens in populations of organisms under "natural selection.”

To imagine how the history of humanly designed artifacts can legitimately be considered a form of "evolution," think of what is common to both natural biological systems (organisms and species) and cultural artifacts: beneath each system lies transmissible information that is used as an instructional template to produce the objectwhether a newborn organism or another cornet of a particular model type. In biology, that information is carried in the large molecules of heredity: DNA and RNA. In the material cultural world, the information is both generated and stored in human minds - in the past 8,000 years or so, often written down and present in drawings. Most of that information nowadays is found on computers.

The key is that the information in both systems is stored and transmitted to the next generation-of organisms, on the one hand, and of makers of artifacts, in the case of humanly designed objects.

So a very general definition of evolution is: the fate of transmissible information through time. I usually like to add the phrase "in an economic context"- as most evolution in the wild concerns the anatomies and physiologies enabling organisms to obtain and utilize energy sources that in turn help them to stay alive and reproduce: things like the 


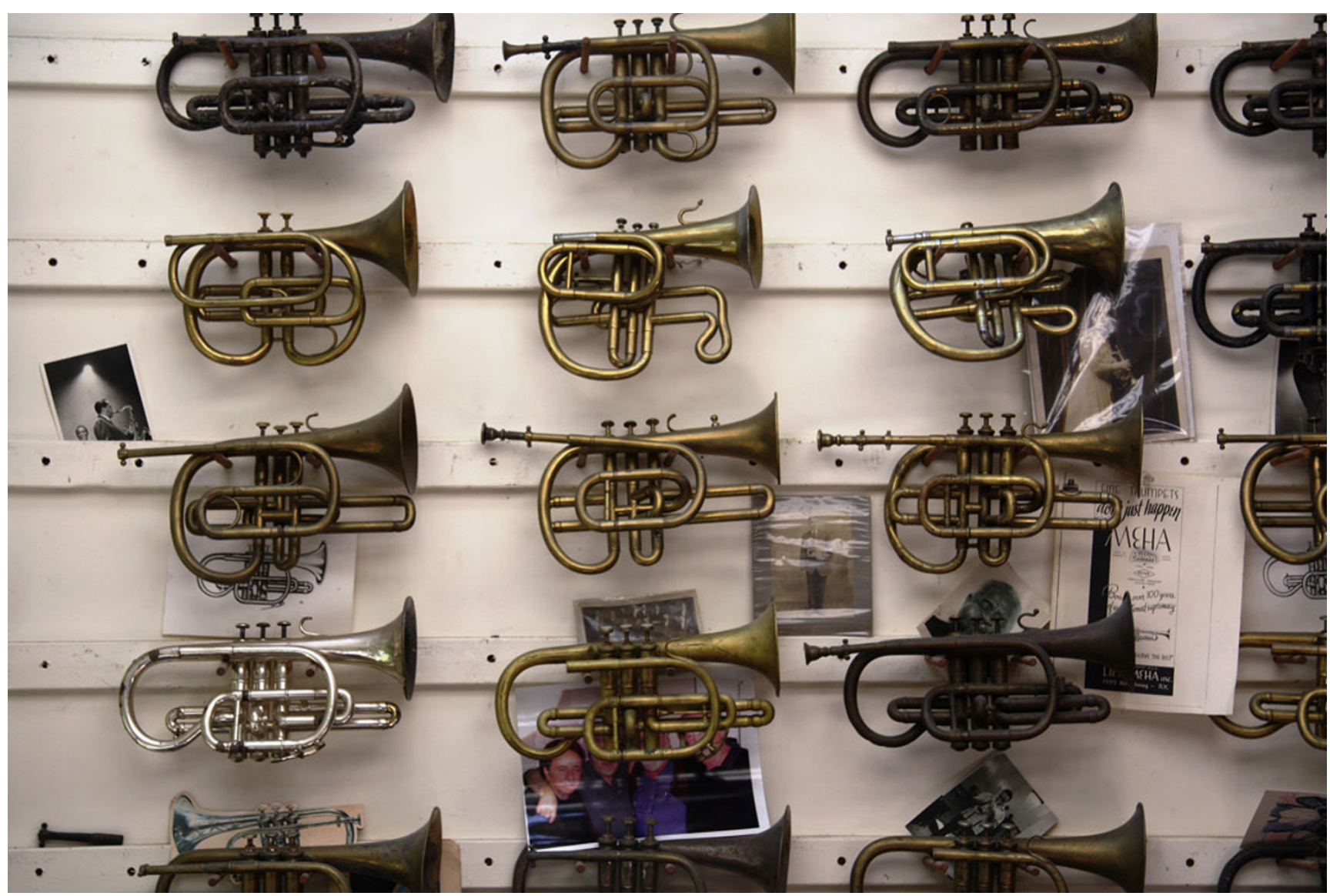

Fig. 1 A portion of the author's "Wall of Cornets" showing some of the different models being made in the early history of cornet design and manufacture

prehensile tails of South American monkeys, the fangs of tigers - or the large thinking brains and opposable thumbs of human beings. These are all adaptations that enable organisms to do the things they do to live in the world. Without our brains and grasping hands that can manipulate, humans simply could not make the great diversity of artifacts we take for granted in our daily lives.

Likewise with artifacts: people design and make thingstools in the broadest sense of the term-most often to help them perform certain tasks. Artifacts serve purposes - and even the production of sweet sounds on a cornet during its heyday in the Victorian era performed the useful functions of providing music in a pre-radio era, and livelihoods for those who made and some who played them.

\section{Adaptation vs. Design in Biological and Material Cultural Evolution}

Darwin professed great admiration for William Paleyauthor of the influential treatise Natural Theology; $\mathrm{Or}$, Evidences of the Existence and Attributes of the Deity, Collected from the Appearances of Nature (Paley 1802).
Paley acknowledged the often spectacular fit between organisms and their environments - the very structures and functions that Darwin ultimately successfully demonstrated are the products of natural processes of selection of heritable variation. Paley made the case that such seemingly perfect fit between organisms and nature was de facto evidence that God had designed and created all the different organisms of the world. After all, he argued, were we to discover a watch on the ground, we would know that it must have had a designer, a builder. By analogy, Paley said, we should realize that a creative mind - the Mind of the Deity-lies behind the intricate designs we see in the organic world.

When Darwin was taking a hard look at evolutionary ("transmutational") ideas as he collected fossils and living species in South America from 1832 to 1835 (see Eldredge 2009a), he saw patterns of replacement in time and space of closely similar species - concluding by journey's end that natural processes underlay the generation of new species. It was only after he reached home that he confronted the problem of adaptation, for the features of organisms must evolve by natural processes - if it is true (as he had decided) that species have births and deaths, analogous to 
those of individuals ("Brocchi's analogy"; see Dominici and Eldredge 2010) through natural causes.

Because Darwin's theory has come down to us as basically a theory of adaptation, historians have naturally assumed that it was adaptation that convinced Darwin to accept evolution in the first place. But Darwin had two stumbling blocks: (1) Paley's arguments that adaptation implies design by the creative Mind of the Deity and (2) the simple fact that, when one looks at any organism alive today, one can marvel at the features that fit them so well to their natural surroundings - but that is all. There is nothing intrinsic about the features of a single organism that demonstrate, in and of themselves, that they evolved through natural causes - rather than being designed by the Deity.

Darwin had one example while on the Beagle that showed that, even in 1832, he was looking for a natural causal understanding of the adaptations of organisms (see Eldredge, 2009a for details of Darwin's encounter with, and thoughts about, this impressive snake species). The large poisonous snake he saw and collected at Bahia Blanca, Argentina in 1832 caught his attention; the tip of the tail was a hardened pointed structure which struck Darwin as intermediate between the simple smooth end of an Old World adder's tail, on the one hand, and the rattle of New World rattlesnakes - which Darwin called the "more perfect" organ. As he wrote in his diary, the tail of his Bahia Blancan fer de lance "marks the passage" between the primitive tails of adders and the advanced, perfected rattles of rattlesnakes.

"Marks the passage" is about motion, of coursebespeaking a sort of fluid interconnectedness between different forms of the "same" (i.e., "homologous") part of different, yet "closely allied," species. Lamarck (1801) had been talking about how the features of organisms slowly are transformed naturally through time, right around the same period as Paley was developing his supernatural explanation of adaptations. But the snake was the clearest of very few such examples that Darwin recorded in his notes while on H.M.S. Beagle. Otherwise, he had really very little to say about adaptations while collecting in the field.

But, once he did arrive home, by now convinced of evolution, Darwin started looking for the natural process that could produce such exact (and some not-so-exact) matches between organisms and their environments. He read and thought about what was known about reproduction, heredity, and variation. And, as he records in his autobiography, after he read about the natural controls on population growth caused by lack of sufficient food supplies and other factors in Thomas Malthus' Essay on Population (Malthus 1798), he suddenly "saw" the principle of what he called "natural selection": because more organisms are produced each generation than will be able to survive and themselves reproduce (else, Darwin once wrote, the world would be "standing-room-only" in elephants), only those most closely suited to their environments will tend to survive and successfully reproducetransmitting to their offspring the features that made them successful (though no one knew at that point in the late 1830s how and why inheritance actually works in biological systems). When new environments are encountered, different variants in the population will then become "favored" by the natural process of selection.

Adaptation through natural selection has been observed in the wild, generated experimentally in the lab, and emulated in mathematical simulations. It is one of the closest things to a natural "law" in evolutionary biology (geographic speciation is an example of another such "statistical law"). Thus, our modern understanding of adaptation is thoroughly vetted science. And that is the reason why we can look at our hands and think about our brains and confidently assert that they are, indeed, the result of natural processes - rather than the direct design product of a supernatural God. Supernatural explanations lie outside the realm of science. Science looks for natural causes of natural phenomena - and natural selection is the natural causal explanation of adaptation.

The marketplace and the experiences of people using artifacts, likewise, impose forms of selection of artifacts. Sometimes "better mousetraps" do come along — but accurate predictions of, for example, which among similar-performing cell phones will dominate the sales - always an elusive Holy Grail for manufacturers and marketers who would love to know in advance what product will succeed, and what will fail -are notoriously hard to come by. "Selection" among alternate variants of an artifact, it seems, is likely to reside as much in a fickle public's mass decision on what is attractive or "cool," as on any clear functional superiority of one version of an artifact over another.

\section{Similarities and Differences Between Biological and Material Cultural Evolution}

One thing I have found from thinking about cornet history as an example of material cultural evolution is that the patterns and processes of evolution in the artifact world, while similar in some respects to biological evolution, are actually in many ways very different from what we see in the evolution of life. Ironically, the human brain - an adaptation that, among many other things, lets us predict what we would see had life in fact have been the product of the Mind of a Deity - allows us to see that intentionally designed systems over time look rather different from the evolutionary histories (phylogenetic trees) that we encounter in the organic world. The neatly nested sets of organisms that are the fallout of the natural evolution of life look very different from patterns of historical evolution of designed systems, something that would have disturbed the Rev. Paley. 
The reason for this disconnect lies, in greatest part, in the differences in the modes of storage and transmission of the particular kinds of information in the organic vs. the material cultural realm. Genes, for the most part, are passed on directly to offspring - in both asexual and sexual modes of reproduction. Hybridization among closely related species is not unknown in some animals (lions and tigers, for example), several groups of plants (e.g., the rose family) and many different microbial taxa-where genetic information can be exchanged between very distantly related groups. But for the most part, at least among multicellular organisms, information is transmitted mostly "vertically," i.e., from parents to offspring.

In contrast, in cultural systems, we learn from our parents - of course - but also from our teachers, friends, and the ambient and increasingly global media. And parents have been known to learn a thing or two from their children. Information moves between members of different generations within families - but also is shared with an ever-widening circle of relatives, friends - up to and including potentially anyone else in the world.

The preponderance of vertical information transmission in the vast majority of multicellular organisms means that evolutionary changes in characters are pretty much restricted to modifications of existing structures - through modification of their genetic bases and developmental expressions. Genetic mutation is the ultimate source of novelty in biological evolution - but again, the vast majority of mutations modify the nature of preexisting structures - rather than produce utterly new features.

Because, along with the presence of conscious design, information is transmitted horizontally as well as vertically in cultural systems, in principle we would expect to encounter much more rapid rates of change in material cultural systems than we see in the multicellular organismic world. Yet patterns of stability ("stasis") alternating with much briefer spurts of actual change are as obvious in the histories of artifact systems as they are in biological evolutionary history.

In the matter of deliberate design, well-studied histories of artifact systems through time repeatedly show innovations that are not the simple, linear modifications of earlier, preexisting structures. If it is often true that makers appropriate (i.e., borrow or steal) the innovative ideas of others, it is also true that those innovations being copied present novel solutions to old problems - a kind of deliberate ad hoc design process that I have called "the Hannah Principle" (see Eldredge 2009b for discussion of this and other aspects of material cultural evolution and for further references; the Hannah Principle is named for furniture designer Bruce Hannah-who first pointed the phenomenon out to me). In this context, it is interesting to think about the use and significance of patents in the modern world. Though patents are taken out to prevent rivals from stealing designs (for example, new medical drugs) for some specified amount of time, they also have the effect of promoting the development of alternate products that have the same or similar uses; patents promote design "evolution" as much as they protect the intellectual property rights of innovative designers.

In biology, similar adaptations have appeared at different times in different groups: birds have wings, but so do mammalian bats - and so did the soaring and flying, nonbird reptiles, the pterosaurs, of the Mesozoic. It might take longer, but biological evolution does provide many examples of independent solutions to the same adaptive problem; in this case, vertebrate flight. But again, most of biological evolution most of the time consists of the modification of preexisting structures within particular lineages.

And therein lies one further enormous difference between biological and material cultural evolutionary systems: lineages are the norm in biological evolutionary history. Although phylogenetic analysis of many species of organisms often yields some conflict in resolution of the placement of some of the species in the system, this is always considered an error of analysis - of confusing true shared evolutionary novelties with homoplasy; instances of shared retention of primitive similarities or the independent acquisition of confusingly similar structures. But for the most part, lineages are clearly demarcated in biological phylogenies. And classification is relatively straightforward, based on the phylogenetic trees that seem to best approximate the actual pattern of biological evolution of particular groups.

In contrast, clear-cut lineages are very hard to come by in artifact systems - especially in the histories of manufactured products (like cornets), where information is transmitted rapidly within and between different makers. Innovative designs are applied by their inventors to a particular product, and often the maker applies the same novelty to other similar artifacts in their product line. And, unless the innovation is patent-protected or when a patent expires, an innovation that is proven successful in the marketplace will rapidly appear in the products of rival makers.

The result is that, for the most part, the phylogenetic trees (or cladograms) of biological evolutionary systems show the relationships of well-defined lineages - and classification of organisms reflects the nested patterns of relationships among major lineages and sublineages.

Diagrams of the histories of artifacts are virtually never as clear-cut. The lateral flow of information produces diagrams that often look more like "networks" than a straightforward ordering of lineages and sublineages. Consequently, classification of artifacts - certainly including musical instruments is far more problematic than biological classification. For example, cornets and trumpets are commonly pitched in the key of B flat-which requires a length of tubing of approximately 4.5 feet. Instead of valves, some instruments of this pitch come equipped with a trombone-like slide. But 
Fig. 2 Valves are added to natural horns. For full explication, see text

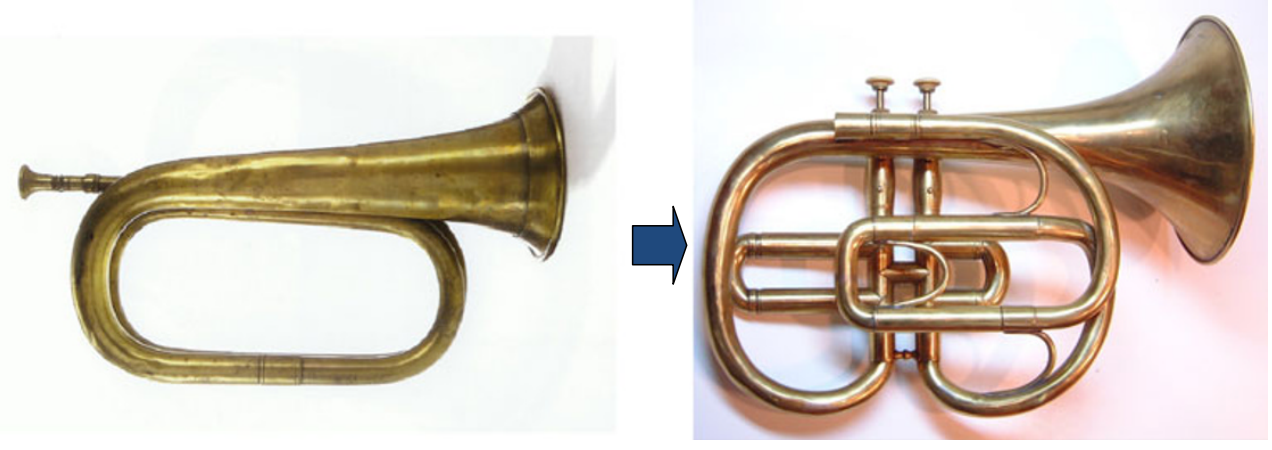

we are left with the problem: is this instrument a high-pitched ("soprano") slide trombone; or is it, instead, a "slide cornet" (or "slide trumpet")? In fact, they have been considered both - depending on their use in different musical settings.

In biology, a frog is a frog - though a few debates still linger over the correct placement of some organisms within a group (not too long ago, people were still arguing whether fruit bats are closely related to insectivorous bats - or rather to our own group - the primates; consensus soon rallied around fruit bats being members of good standing with the other bats in the Order Chiroptera). But in musical instruments - and, by implication, in nearly all manufactured artifact systemsthere is often no definitive answer possible even in principle to what is the "natural" classification of a group of artifacts.

\section{Illustrations of Material Cultural Evolutionary Principles from the History of Cornets}

All of the above thoughts and conclusions on the nature of material cultural evolution - and its similarities to, and differences from, biological evolution-are summarized in the following sequence of illustrations highlighting major features of cornet history and evolution. For more details, see Eldredge (2002) and Eldredge (2009b).

Brass instruments (and their natural equivalents-e.g., the Israeli shofar and African spiral trumpets, both made of animal horns) go back to Neolithic times. Just as in the modern military (and Boy Scout) bugle, the sound is produced by buzzing the lips into a cup-like receiver (a "mouthpiece"); the instrument itself is a resonator, amplifying the sound of the waves produced by the lips. All these instruments produce sounds in the overtone series only (think of taps or reveille): in the lower spectrum of sound, the notes are an octave apart; the notes come closer together the higher the instrument is played. Bach wrote nearly impossibly high pieces playable (to this day) only by virtuosi; on valveless Baroque trumpets, at the extremes of the upper register, the tones come together closely enough to play melodic passages beyond the rigid constraints of the lower registers of these open-toned horns.

To achieve full chromatic scales, ways had to be found to change the length of the instrument. Slides appeared first (in sackbuts - forerunners of modern trombones) and holes were placed (as they were in flutes) on later Baroque trumpets to aid in achieving notes that were in tune. But it was not until the early nineteenth century that metallurgical processes had developed sufficiently to allow the invention of what turned out to be a rather wide variety of possible solutions to the problem of turning a bugle into a chromatic instrument: keys, better slides, and all manner of valves were tried out. For the most part today, cornets and trumpets have either piston or rotary-style valves. Pistons won out over rotary valves quickly in France and in England - and a bit later in the United States. My own collection and research focuses on piston-valved instruments.

- Piston valves were first added to soprano-valved instruments in France in the mid-1820s (Fig. 2). Two

Fig. 3 The third valve is added. For full explication, see text

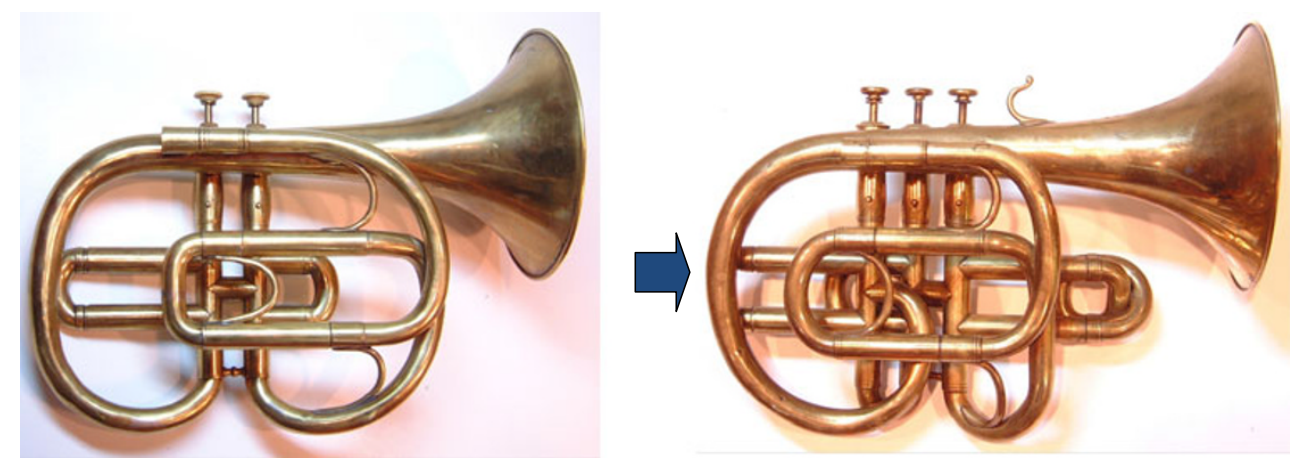


Fig. 4 The Hannah Principle: replacement of Stölzel by Périnet valves. For full explication, see text

Fig. 5 The cornet bell is experimentally shifted to the left of the valves producing the "English bell." For full explication, see text

Fig. 6 Lateral motion of features: retrofitting the English bell to cornets with Stölzel valves. For full explication, see text
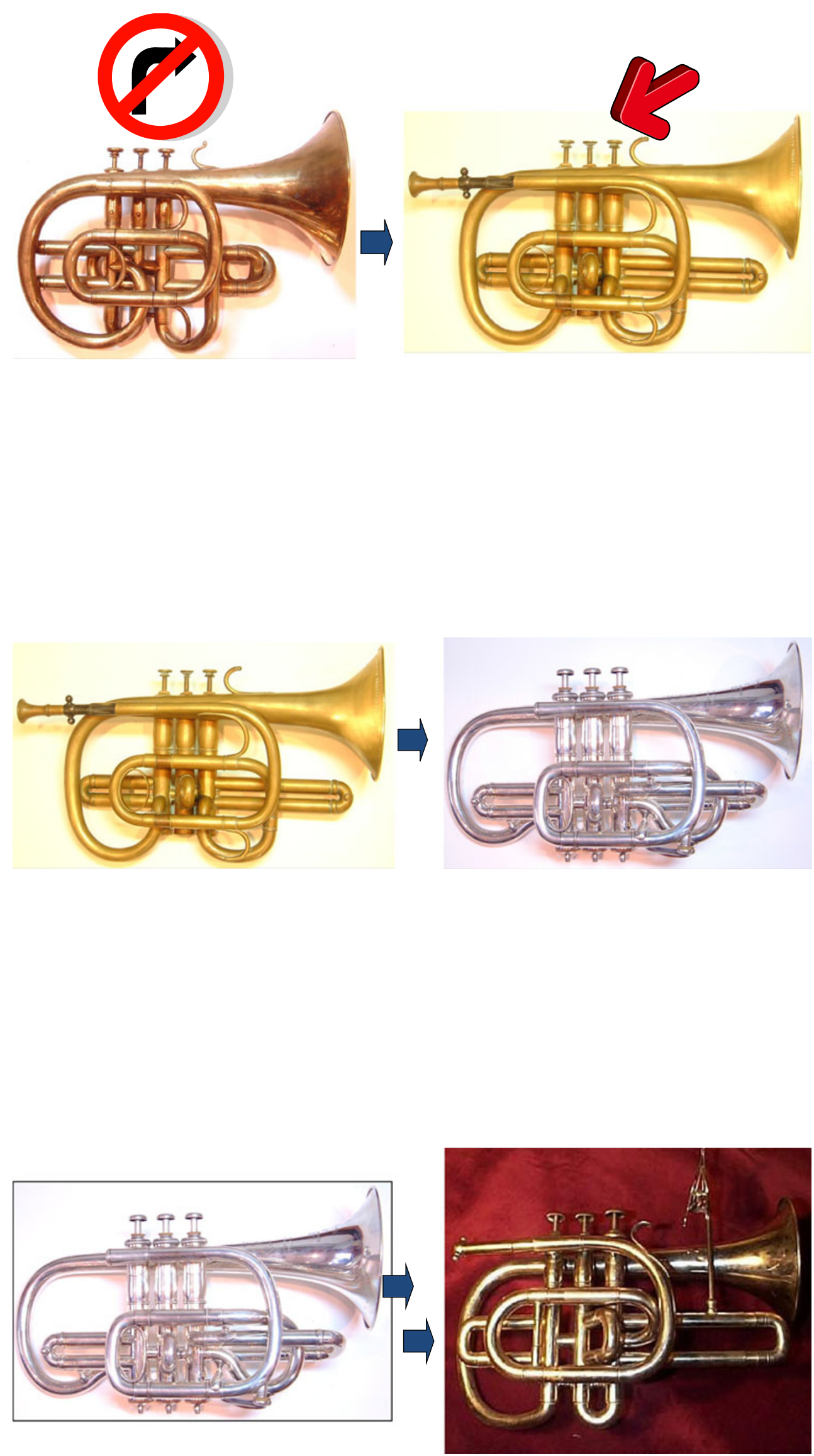


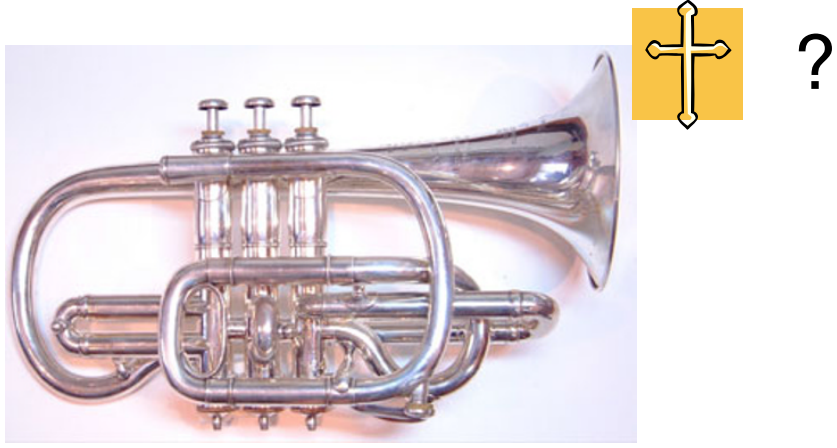

Fig. 7 Virtual extinction of iconic Victorian cornet ca.1900. For full explication, see text

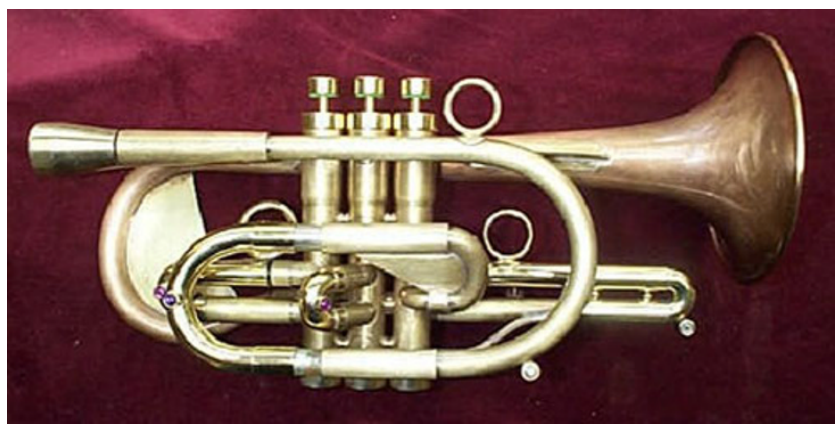

Fig. 8 Return of the shepherd's crook cornet - the "Lazarus effect." For full explication, see text
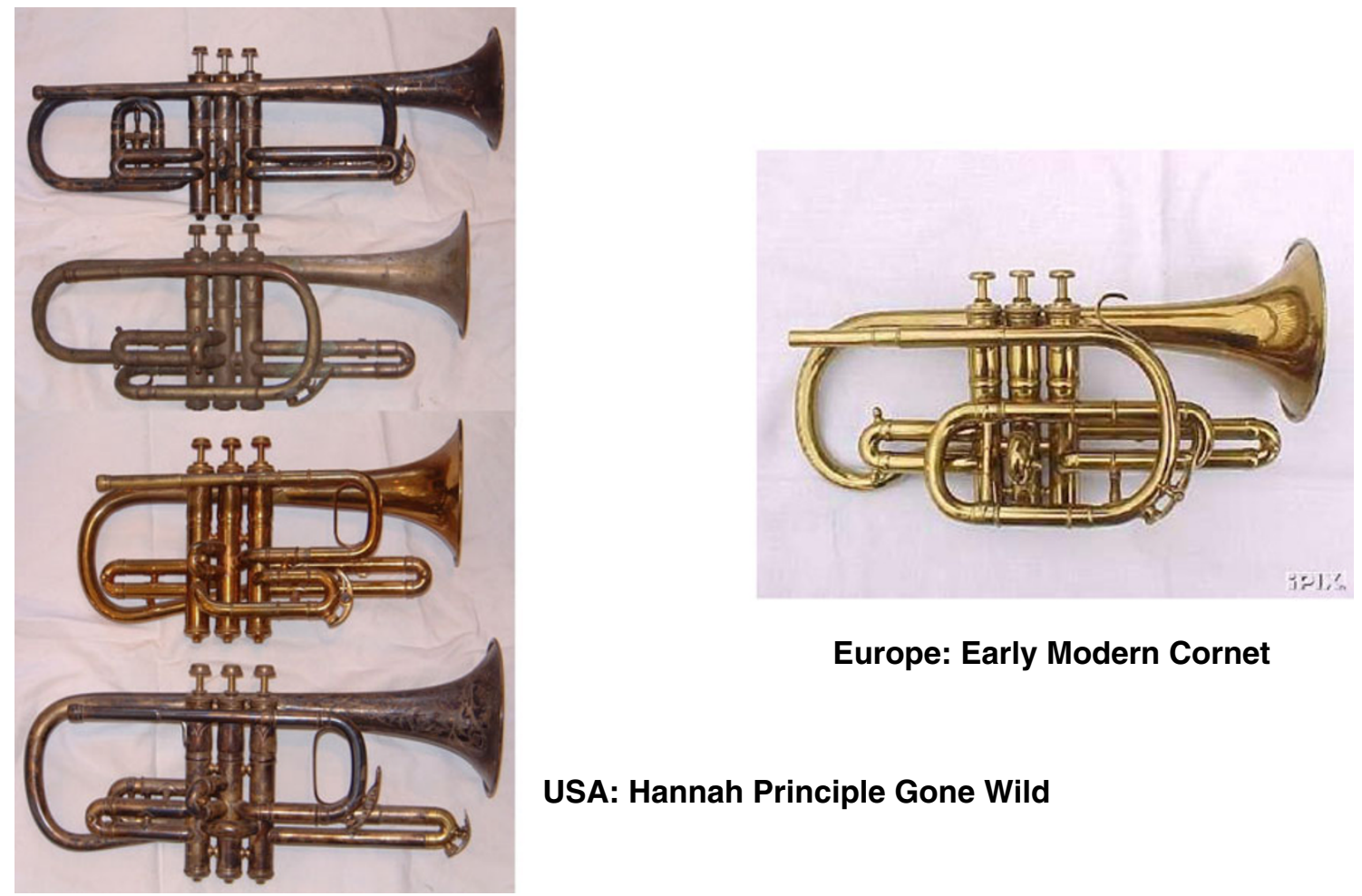

Europe: Early Modern Cornet
"Stölzel" valves-where the windway passes up or down a hollow piston valve before exiting into side loops that lengthen the horn when the valve is depressed - were added to a natural horn. The result is an instrument that can play nearly a full chromatic scale over the entire compass of the instrument-except in the lower register. This is a form of "selection"- as it is highly desirable to have the capability of playing fully chromatically in western music, and Stölzel valved instruments were relatively easy to learn how to play. Exactly why rotary valves remained the preferred choice in German-speaking countries, as well as in Scandinavia, Russia, and Italy-rather than pistonvalved instruments (and vice versa) remains a mystery. Well-made horns with either valve type are still being produced today - and are equally serviceable.

- By the late 1820 s, a third valve was added — completing the achievement of full chromaticism (Fig. 3). This amounts to improving on the less-than-complete chromaticism achieved a few years previously when at first only two valves were added to a natural horn. This is a form of directed variation: a three-valved design that is instantly "selected" by both cornet makers and the musical composing, playing — and listening - public.

- The Hannah Principle (Fig. 4). In the late 1830s, Francois Périnet invented a different type of piston valve - one where the windway passes across a valve,

\section{USA: Hannah Principle Gone Wild}

Fig. 9 Extinction and its aftermath. For full explication, see text 
Fig. 10 Biological-like evolutionary derivation of long bell cornets from short bell cornets. For full explication, see text

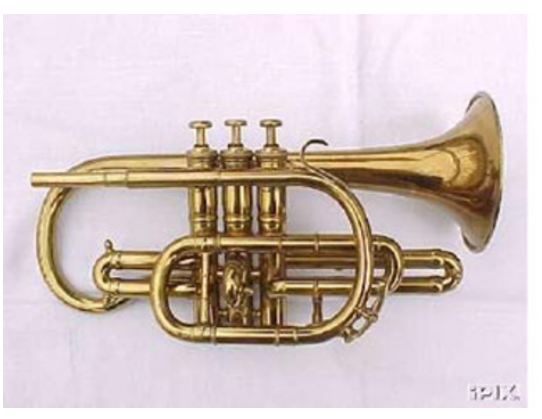

not up and down the interior of the valve. The earliest cornet equipped with Périnet valves known to have survived was made by Adolphe Sax in 1843 in Paris not long after he arrived from Brussels. Though makers claimed that the newer valve removed sharp turns in the windway and thus improved the quality of sound and ease of playing the instrument, experience with wellmade and expertly restored period instruments shows that horns with the older Stölzel valves play and sound as well as those fitted with the new-fangled Périnet valves. The one advantage of the newer valves is that they could be made thicker (Stölzel valves had to have the same internal diameter as the tubing that entered them), making them more robust and less prone to damage. Périnet valves were not "derived" from Stölzel valves: they represent an alternative design of a piston valve-hence the "Hannah Principle."

- Innovation from a single maker (Fig. 5). In an experimental design, around 1855, the Parisian maker Antoine Courtois shifted the "bell" (the final section of tubing, expanding into a circular flare, where the sound is emitted) from the original right-hand side of the valves to the left-hand side. The effect is to improve the grip on the horn by the left hand. This innovation was slow to catch on in France - but was a near-overnight success in Great Britain-becoming known as the "English Bell." From the mid-1850s on, most British horns - whether locally made or imported-featured this English bell, which eventually became the norm for all cornets (and trumpets) made and played in France,

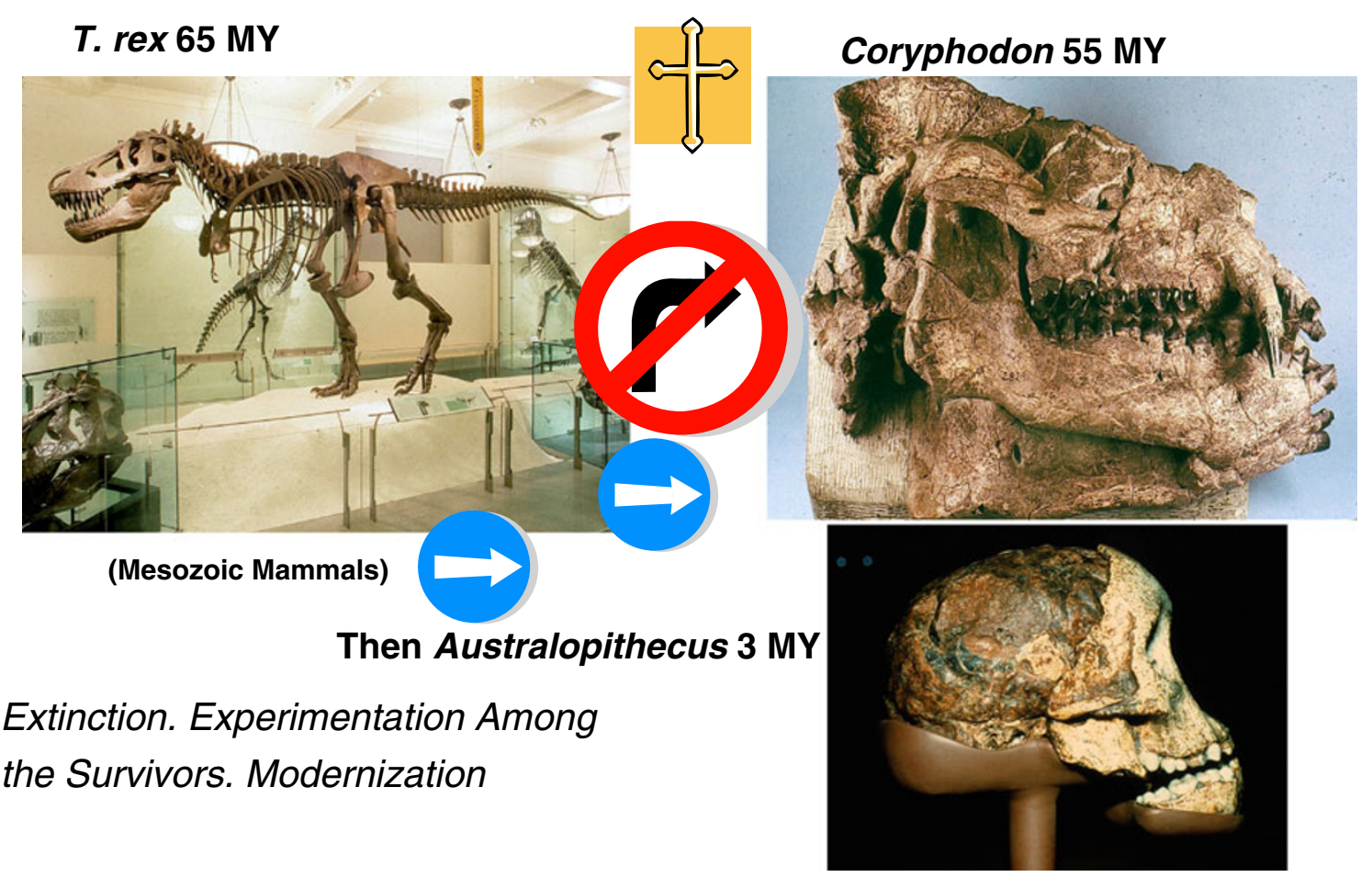

Fig. 11 Large-scale extinction and evolutionary recovery patterns in biological evolution. For full explication, see text 
the United States and other places where piston-valved comets were and still are being played.

- Lateral movement ("theft of idea") of a design innovation (Fig. 6). Once the "English bell" had appeared, makers began to shift the bell to the left of the Stölzel-valved cornopeans - the cornets with the earlier form of piston valve that by the 1860 s were still being produced, as the less-expensive models.

- Extinction of a dominant design (Fig. 7). Evolution in the organic realm involves "births and deaths" of species. New species evolve, but all are eventually destined to become extinct. The same is true for cornet model designs. The iconic Victorian cornet was designed and sold initially by the Courtois firm in Paris-but was immediately wildly copied ("theft of idea") by many other makers, many as cheap "knockoffs" from 1855 throughout the remainder of the nineteenth century. This relatively long period of little or no change in the design of the dominant model of cornets represents a period of significant "stasis" in material cultural evolution-very much like the long periods of stability seen in many species in the fossil record. Then, abruptly, right about 1900, the design all but disappeared; even Courtois made very few. The reason for this change was not the introduction of a rival new design - but apparently the fickle tastes of the public: The dawn of the new twentieth century simply brought a taste for "modern" designs_-yet another example of the fate of a particular cornet design based not on the actual musical playing qualities of the instruments - but rather their outward appearance.

- The "Lazarus Effect"-extinction is not necessarily forever in artifact evolution (Fig. 8). Once the last member of a species dies_like Martha, thought to be
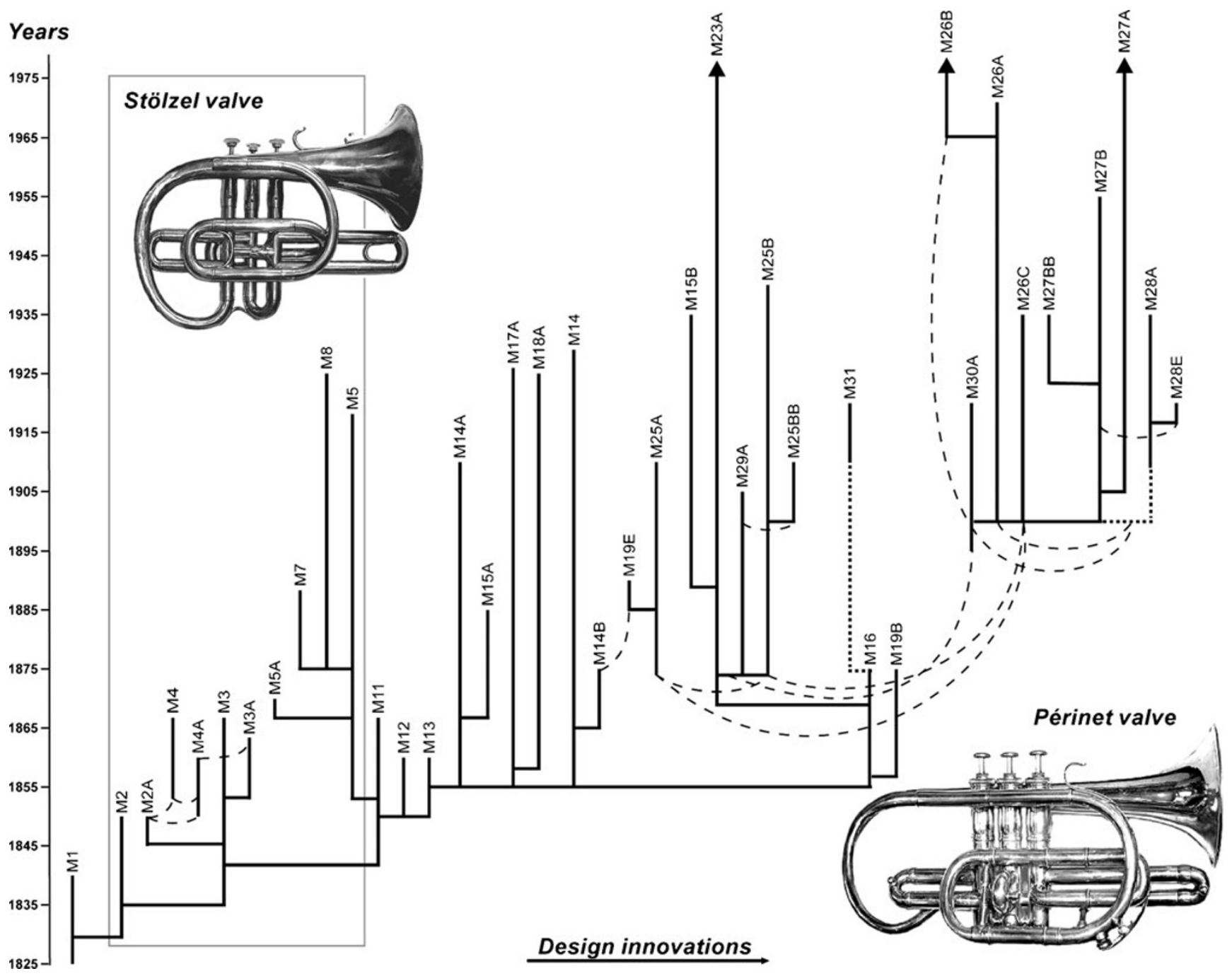

Fig. 12 Lateral transfer muddies phylogeny in material cultural evolution. Vertical lines represent distinct cornet models-described numerically. For full explication, see text. Redrawn from Tëmkin and Eldredge 2007, Fig. 2 and modified by Ilya Temkin 
the last passenger pigeon, who lived in the Cincinnati Zoo until she died in 1914 - that's it; the species is gone forever. Not so for material cultural artifacts, which can be reinvented —or, better still, deliberately resurrectedbased on surviving information: whether from old horns, catalogs or patent drawings, etc. This instrument - with some modern filigrees - is one of many current resurrections of the old "shepherd's crook" design (referring to the deep bend in the bell as it exits the valves) that dominated the latter half of the nineteenth century.

- Extinction's Aftermath: Hannah Principle experimentation gone wild in the U.S., adoption of a pre-existing alternative nineteenth century shepherd's crook design in France and England (Fig. 9). In the United States, the turn of the century, with the virtual demise of the old fashioned Victorian short-model shepherd's crook cornets, ushered in an era of experimentation lasting until the United States entered World War I. "Planned obsolescence" became the preferred marketing strategy. "New and improved" was in nearly every maker's advertising - and some companies (such as G.C. Conn) brought out new versions of their models nearly every year. All of these new designs have novel valve configurations and tuning slide arrangements. Meanwhile, in Europe with the decline of the Courtois shepherd's crook cornets, the simpler design of the Besson company-a design that had been present in "English bell" models since the mid-1860s - became the dominant style, at least for the first decade or so of the twentieth century.

- Evolution by simple modification of preexisting conditions (Fig. 10). The surviving Besson-style short-bell cornet of the early twentieth century was elongated by many makers on both sides of the Atlantic around 1915. This shows that, like much of biological evolution, new designs are often produced by simple modification of preexisting designs in artifact evolution. This "longbell" cornet quickly became the dominant model until recentlyreplacing most of the wild American design of the first decades of the twentieth century. Nowadays, nostalgia has gripped the cornet world, and the shepherd's crook design is back in favor - the "Lazarus effect" of Fig. 8.
- Extinction, followed by experimentation and "modernization" in biological evolution (Fig. 11). The pattern in cornet evolutionary history of end-nineteenth century extinction, followed by experimentation and eventual modernization, is effectively paralleled by patterns of biological events surrounding major mass extinctions. After the final demise of the non-avian dinosaurs and some other reptilian groups at the end of the Cretaceous, mammals (which had existed as long as the dinosaurs throughout much of the Mesozoic) began to radiate, and an array of early mammals, themselves doomed to fairly early extinction, effectively took their place - eventually to be replaced by early members of modern mammalian groups.

- Lateral transfer of information makes diagrams of artifactual history messy (Fig. 12). This "reticulogram" outlining cornet history in evolutionary terms shows many of the pathways where information is known to have spread across "lineages" by horizontal transfer ("theft of idea" etc.).

\section{References}

Dominici S, Eldredge N. Brocchi, Darwin, and transmutation: phylogenetics and paleontology at the dawn of evolutionary biology. Evo Edu Outreach. 2010;3:576-84. doi:10.1007/s12052010-0280-7.

Eldredge N. A brief history of piston-valved cornets. Hist Brass Soc J. 2002;14:337-90.

Eldredge N. Experimenting with transmutation: Darwin, the Beagle and evolution. Evo Edu Outreach. 2009a;2:35-54. doi:10.1007/ s12052-008-0103-2.

Eldredge N. Material cultural macroevolution. In: Prentiss AM, et al., editors. Macroevolution in human prehistory. 2009b;297-316 (Ch. 12). doi:10.1007/978-1-4419-0682-3 12.

Lamarck J-B. Système des animaux sans vertèbres. Paris; 1801

Malthus TR. An essay on the principle of population, as it affects the future improvement of society. London: J. Johnson; 1798.

Paley W. Natural theology: or, evidences of the existence and attributes of the Deity, collected from the appearances of nature. London: R. Fauldner; 1802.

Tëmkin I, Eldredge N. Phylogenetics and material cultural evolution. Curr Anthropol. 2007;48(1):146-53. 